\title{
Inflammasome-Dependent Cytokines at the Crossroads of Health and Autoinflammatory Disease
}

\author{
Hanne Van Gorp, ${ }^{1,2}$ Nina Van Opdenbosch, ${ }^{1,2}$ and Mohamed Lamkanfi ${ }^{1,2}$ \\ ${ }^{1}$ Center for Inflammation Research, VIB, Zwijnaarde B-9052, Belgium \\ ${ }^{2}$ Department of Internal Medicine, Ghent University, Ghent B-9000, Belgium \\ Correspondence: mohamed.lamkanfi@irc.vib-ugent.be
}

As key regulators of both innate and adaptive immunity, it is unsurprising that the activity of interleukin (IL)-1 cytokine family members is tightly controlled by decoy receptors, antagonists, and a variety of other mechanisms. Additionally, inflammasome-mediated proteolytic maturation is a prominent and distinguishing feature of two important members of this cytokine family, IL-1 $\beta$ and IL-18, because their full-length gene products are biologically inert. Although vital in antimicrobial host defense, deregulated inflammasome signaling is linked with a growing number of autoimmune and autoinflammatory diseases. Here, we focus on introducing the diverse inflammasome types and discussing their causal roles in periodic fever syndromes. Therapies targeting IL-1 or IL-18 show great efficacy in some of these autoinflammatory diseases, although further understanding of the molecular mechanisms leading to unregulated production of these key cytokines is required to benefit more patients.

\begin{abstract}
$T^{\text {he }}$ he interleukin (IL)-1 cytokine family plays a central role in both innate and adaptive immunity because its many members exert a wide range of biological functions. The importance of these cytokines is underscored by the fact that their activity is tightly controlled through selective protein synthesis, the requirement for proteolytic processing, as well as the existence of receptor antagonists, decoys, and intracellular signaling inhibitors. Disturbance, however, of this well-oiled machinery leads to malfunctioning and ultimately may instigate or contribute to the onset of clinical or subclinical disease. In this review, we will highlight two prominent IL-1 cytokines, IL-1 $\beta$ and IL-18, that share the re-
\end{abstract}

quirement for proteolytic maturation by a set of multiprotein complexes named inflammasomes. Apart from providing an overview of their roles in maintaining homeostasis, we will focus the discussion on their contributions to autoinflammatory diseases.

\section{IL-1 CYTOKINE FAMILY}

The IL-1 family consists of seven proinflammatory cytokines (IL-1 $\alpha$, IL-1 $\beta$, IL-18, IL-33, IL-

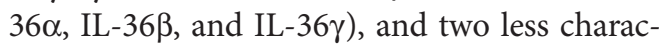
terized family members (IL-37 and IL-38) that were suggested to act as antagonists within the IL-1 cytokine family (Table 1) (Lin et al. 2001;

Editors: Warren J. Leonard and Robert D. Schreiber

Additional Perspectives on Cytokines available at www.cshperspectives.org

Copyright (C) 2019 Cold Spring Harbor Laboratory Press; all rights reserved; doi: 10.1101/cshperspect.a028563

Cite this article as Cold Spring Harb Perspect Biol 2019;11:a028563 
H. Van Gorp et al.

Table 1. Interleukin (IL)-1 cytokine family members with their receptors, antagonists, and main functions

\begin{tabular}{|c|c|c|c|}
\hline Cytokine & Receptor/coreceptor & Antagonist/decoy & Function \\
\hline IL- $1 \alpha(\mathrm{IL}-1 \mathrm{~F} 1)$ & IL-1R1/IL-1RAcP & IL-1Ra/IL-1R2 & Alarmin, Th17 response \\
\hline IL-1 $\beta$ (IL-1F2) & IL-1R1/IL-1RAcP & IL-1Ra/IL-1R2 & Inflammation, fever, Th17 response \\
\hline IL-18 (IL-1F4) & IL-18R $\alpha / \mathrm{IL}-18 \mathrm{R} \beta$ & IL-18BP & Inflammation, Th1 response \\
\hline IL-33 (IL-1F11) & ST2/IL-1RAcP & sST2 & Inflammation, Th2 response \\
\hline IL-36 $\alpha(\mathrm{IL}-1 \mathrm{~F} 6)$ & IL-36R/IL-1RAcP & IL-36Ra & Proinflammatory functions \\
\hline IL-36ß (IL-1F8) & IL-36R/IL-1RAcP & IL-36Ra & Proinflammatory functions \\
\hline 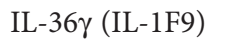 & IL-36R/IL-1RAcP & IL-36Ra & Proinflammatory functions \\
\hline IL-37 (IL-1F7) & IL-18R $\alpha$ & Unknown & IL-18 antagonist \\
\hline IL-38 (IL-1F10) & IL-36R & Unknown & IL-36 antagonist \\
\hline
\end{tabular}

Sharma et al. 2008; Palomo et al. 2015). All IL-1 cytokine family members are composed of an amino-terminal prodomain with variable length and a carboxy-terminal cytokine domain. Apart from IL-18 and IL-33, all genes encoding IL-1 cytokines are located on syntenic regions of human and mouse chromosome 2 (Taylor et al. 2002). The gene for human IL-37 also resides in this cluster, although a murine homolog has not been identified (Boraschi et al. 2011). Unlike most cytokines, the full-length gene products of several IL-1 cytokines (IL-1 $\beta$, IL-18, IL-36 $\alpha$, IL$36 \beta$, and IL-36 $\gamma$ ) are biologically inert, and proteolytic processing by a select number of proteases (e.g., caspase-1, caspase-8, proteinase-3, elastase, calpain, cathepsin G, and granzyme B) greatly enhances their biological activity. In contrast, IL-1 $\alpha$ and IL-33 are synthesized as constitutively active cytokines, although their immunostimulatory activity can be further amplified by proteolytic processing (Afonina et al. 2011; Lefrancais et al. 2012).

Besides these agonistic molecules, several receptors, coreceptors, antagonists, and decoy receptors (e.g., IL-1R1, IL-18R $\alpha$, IL-18R $\beta$, IL-1Ra, IL-36Ra, IL-1R2, and IL-18BP) that either promote or dampen immune signaling by IL-1 family cytokines have been characterized (Table 1 ). Analogous to IL- $1 \alpha$ and IL- $1 \beta$ that bind to IL1R1, IL-1Ra functions as a receptor antagonist by binding with similar affinity to the receptor and blocking its signaling (Dripps et al. 1991; Schreuder et al. 1997). IL-36 binds to IL-36R, which akin to IL-1R1 uses IL-1RAcP as a coreceptor. IL-18 interacts with IL- $18 R \alpha$ and uses IL-18R $\beta$ as a coreceptor. IL-18BP is a se- creted protein that binds and neutralizes mature IL-18 in circulation (Novick et al. 1999). Its expression is up-regulated by a combination of proinflammatory cytokines, suggesting that it serves as a negative feedback loop to dampen IL-18 functions (Corbaz et al. 2002). Moreover, IL-1R2 was found to bind with high affinity to IL- $1 \alpha$ and IL-1 $\beta$, but because of the lack of a Toll/IL-1 receptor (TIR) domain, downstream signaling is blocked (McMahan et al. 1991). The IL-1 family thus not only contains potent proinflammatory cytokines, but also several checkpoints and mechanisms to dampen IL-1mediated inflammation (Fig. 1).

Unlike IL- $1 \alpha$ that is synthesized by epithelial cells of the gastrointestinal tract, lung, liver and kidney, endothelial cells, and keratinocytes, cells of the myeloid lineage are the main source of IL$1 \beta$. In contrast, IL-18 is constitutively expressed by most cell types. IL-1Ra is produced by cells that also express IL- $1 \alpha$ and IL- $1 \beta$, and the same holds true for IL-18 and IL-18BP (Dinarello 1996). The widespread expression profiles of these cytokines hints toward key roles in innate and adaptive immunity. In this review, we focus on members of the IL-1 cytokine family linked to inflammasome signaling. For further information on inflammasome-independent regulation of IL-1 family members, please see the review by Netea et al. (2015).

\section{INFLAMMASOME-DEPENDENT PROCESSING OF IL-1 CYTOKINES}

Unprocessed IL- $1 \alpha$ is constitutively active but caspase-1-dependent proteolytic processing of 
Inflammasome-Dependent Cytokines in Health and Disease

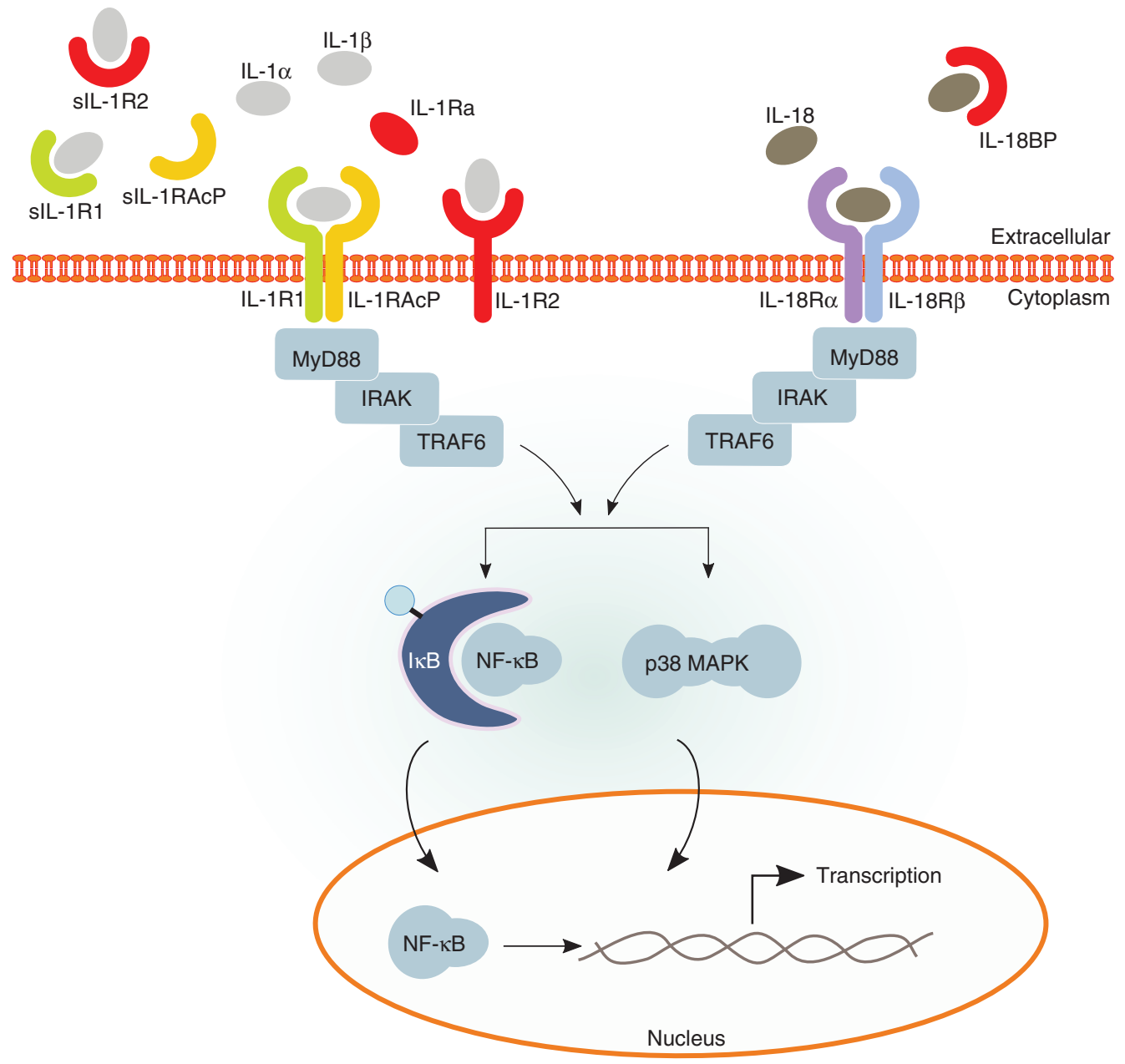

Figure 1. Interleukin (IL)-1 $\alpha$, IL-1 $\beta$, and IL-18 receptor complexes and downstream signaling. Pro-IL-1 $\alpha$, mature IL- $1 \alpha$, and mature IL-1 $\beta$ can all bind to IL- 1 receptor 1 (IL-1R1), which enables recruitment of the IL- 1 receptor accessory protein (IL-1RAcP) coreceptor. Approximation of the intracellular Toll/IL-1 receptor (TIR) domains of the IL-1R complex results in recruitment of MyD88 followed by a cascade of downstream events that ultimately result in the activation of important signaling proteins, such as mitogen-activated protein kinases (MAPKs, e.g., p38), as well as transcription factors, including nuclear factor (NF)- $\mathrm{B}$, which control expression of a number of inflammatory genes. Signaling through the IL-1R complex is modulated by inhibitory actions of membranebound IL-1R2, soluble IL-1 receptor antagonist (IL-1Ra), and soluble forms of the receptors (sIL-1R1, sIL-1R2, and sIL-1RAcP). On binding of IL-18 to IL-18R $\alpha$, IL-18R $\beta$ then is recruited to the complex. Similar to the IL-1R complex, approximation of the two receptors results in recruitment of MyD88 and a downstream cascade activating signaling proteins and transcription factors. Signaling through the IL-18R complex is modulated by inhibitory actions of IL-18 binding protein (IL-18BP).

IL-1 $\beta$ and IL-18 is required for gaining biological activity (Afonina et al. 2011). When produced locally in inflamed tissues, IL-1 $\beta$ mainly functions to stimulate leukocyte activation. Because systemic IL-1 $\beta$ is a prominent inducer of fever and acute phase proteins, which at high levels may even trigger systemic inflammatory response syndrome, its levels in circulation must be tightly regulated (Fig. 1). Indeed, IL-1 $\beta$ is hardly detected in serum, which is probably be- 
H. Van Gorp et al.

cause of its short half-life, as well as its rapid neutralization by soluble IL-1R1 and IL-1R2 (Smith et al. 2003; Lachmann et al. 2009; Gabay et al. 2010). IL-18, on the other hand, is readily detectable in serum, and homeostatic levels appear to correlate with age (Kleiner et al. 2013). Similar to IL-1 $\beta$, IL-18 is sequestered and neutralized in circulation, in this case by soluble IL18BP (Dinarello et al. 2013).

Caspase-1, the founding member of the vertebrate cysteine aspartate-specific protease family, processes IL-1 $\beta$ into a $17 \mathrm{kDa}$ mature fragment (Howard et al. 1991). Similarly, caspase-1mediated proteolytic processing of IL-18 results in a mature product of $17.2 \mathrm{kDa}$ that is released extracellularly (Ghayur et al. 1997; Gu et al. 1997). Not only are the cytokines IL- $1 \beta$ and IL18 themselves expressed as inactive proforms, but caspase- 1 is also expressed as a cytosolic inactive zymogen. It gains proteolytic activity through proximity-induced conformational changes imposed by its recruitment in inflammasome complexes. Under physiological conditions, this results in caspase- 1 autocleavage and enhanced cleavage of IL-1 $\beta$ and IL-18, although genetic studies have shown that caspase- 1 automaturation is dispensable for caspase- 1 protease activity (Broz et al. 2010; Van Opdenbosch et al. 2014).

Inflammasomes are defined as caspase-1activating complexes. They are assembled in response to infections, pathogen-associated molecular patterns (PAMPs), and cellular stress. Major outcomes of inflammasome activation are a lytic form of cell death called pyroptosis and the concomitant release of IL-1 cytokines and alarmins/danger-associated molecular patterns (DAMPs) such as high-mobility group box 1 protein (HMGB1). Several members of the nucleotide-binding domain and leucinerich repeat (NLR)-containing receptor family, when responding to intracellular danger, initiate the formation of the inflammasome. Also, AIM2 (absent in melanoma 2), a member of the HIN200/AIM2-like receptor (ALR) family, is an inflammasome sensor (Fernandes-Alnemri et al. 2009; Rathinam et al. 2010; Sauer et al. 2010; Choubey 2012; Jin et al. 2012). More recently, a member of the tripartite motif
(TRIM) family, Pyrin/TRIM20, was shown to assemble a functional inflammasome (Xu et al. 2014). To date, five distinct inflammasomes, named after the sensor, have been genetically validated in mice studies (Fig. 2). Although in humans only one NLRP1 gene exists, mice encode three paralogs: Nlrp1a, Nlrp1b, and Nlrp1c (Boyden and Dietrich 2006). Gain-of-function mutations in Nlrpla were shown to cause leukopenia and anemia in mice as a result of unwarranted inflammasome activation in bone marrow cells (Masters et al. 2012). Bacillus anthracis lethal toxin is the only defined biochemical agent that activates the NLRP1b inflammasome (Boyden and Dietrich 2006). Contrastingly, the NLRP3 inflammasome responds to a large set of molecules and insults. Uniquely, the NLRP3 inflammasome requires a two-step mechanism for activation. First TLR-priming provides for nuclear factor (NF)- $\kappa \mathrm{B}$-mediated transcriptional up-regulation of NLRP3 itself and pro-IL-1 $\beta$ (Bauernfeind et al. 2009). This sets the scene for NLRP3 activation through incompletely understood mechanisms on subsequent exposure to pore-forming agents, crystals, $\beta$-amyloids, and many other products. Indeed, DAMPs like extracellular ATP and hyaluronic acid; medically relevant crystalline products such as alum, CPPD, MSU, silica, and asbestos; ionophores such as nigericin; and $\beta$-fibrils can all trigger assembly of the NLRP3 inflammasome (Mariathasan et al. 2006; Martinon et al. 2006; Halle et al. 2008; Hornung et al. 2008). Moreover, the major component of the outer membrane of Gram-negative bacteria, lipopolysaccharide (LPS), was shown to activate NLRP3 through a noncanonical pathway involving caspase- 11 . On detection of intracellular LPS, caspase-11 autonomously induces pyroptosis, and through the NLRP3 inflammasome triggers caspase-1dependent IL-1 $\beta$ and IL-18 maturation (Kayagaki et al. 2011; Shi et al. 2014). Intracellular detection of bacterial flagellin or specific type III secretion systems (T3SS) of, for example, Salmonella enterica serovar Typhimurium results in activation of the NLRC4 inflammasome. Cytosolic recognition of these bacterial factors by members of the NLR family apoptosis inhibitory protein (NAIP) cluster within the NLR fam- 


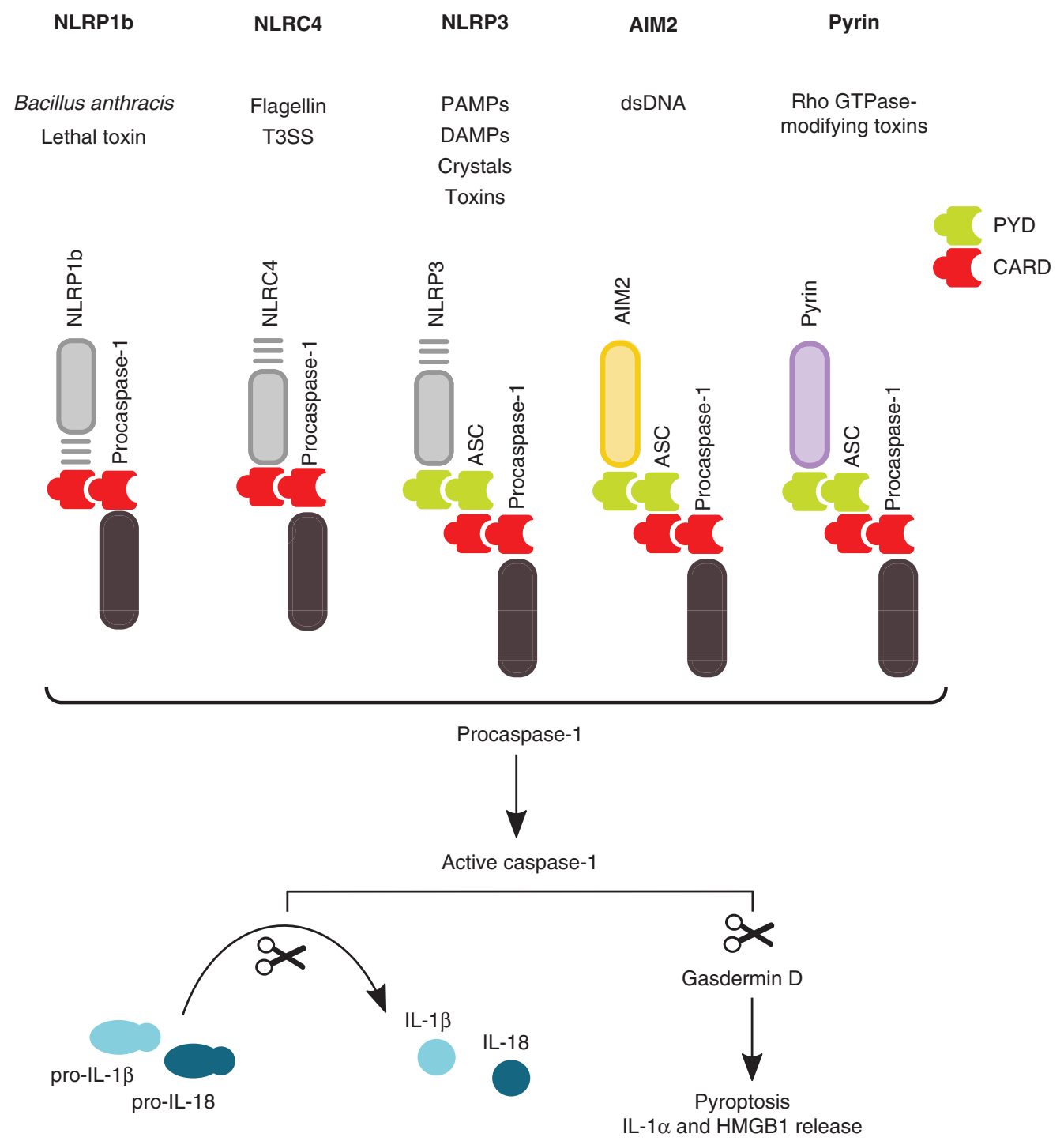

Figure 2. Schematic representation of inflammasome triggers and signaling events. Inflammasome-assembling proteins including the nucleotide-binding domain and leucine-rich repeat (NLR) containing family members NLRP1b, NLRC4, and NLRP3, as well as AIM2 and Pyrin detect, directly or through a secondary messenger, the presence of a pathogen and/or cellular damage. This results in their oligomerization and inflammasome assembly in which inactive procaspase-1 precursors are recruited. Although the PYD-based NLRP3, AIM2, and Pyrin platforms require the bipartite adaptor protein ASC to recruit caspase-1, the caspase recruitment domain (CARD)-based NLRP1b and NLRC4 inflammasomes recruit caspase-1 independently of ASC. Oligomerization of procaspase- 1 leads to its autoactivation, and active caspase- 1 catalyzes the maturation and secretion of the inflammatory cytokines interleukin (IL)- $1 \beta$ and IL-18. Additionally, active caspase-1 engages pyroptosis by cleaving its substrate gasdermin D. This lytic mode of programmed cell death coincides with the release of alarmins such as IL- $1 \alpha$ and high-mobility group box 1 protein (HMGB1). T3SS, Type III secretion system; PAMPs, pathogen-associated molecular patterns; DAMPs, danger-associated molecular patterns; dsDNA, double-stranded DNA. 
H. Van Gorp et al.

ily-along with Ser533 phosphorylation of NLRC4-mediates NLRC4 inflammasome activation (Mariathasan et al. 2004; Lightfield et al. 2011; Qu et al. 2012; Matusiak et al. 2015). On cytosolic recognition of viral (e.g., vaccinia virus), bacterial (e.g., Francisella tularensis and Listeria monocytogenes) or host-derived double-stranded DNA (dsDNA), the AIM2 inflammasome is assembled (Fernandes-Alnemri et al. 2010; Kim et al. 2010; Rathinam et al. 2010; Di Micco et al. 2016; Hu et al. 2016). Finally, it was recently established that RhoA GTPase-inactivating modifications induced by various bacterial toxins (e.g., Clostridium difficile) indirectly trigger activation of the Pyrin inflammasome (Xu et al. 2014).

Although a wide variety of PAMPs and DAMPs are able to trigger selective inflammasome assembly, the downstream effectors are largely equal in all inflammasomes (Fig. 2). The inflammasome adaptor apoptosis-associated speck-like protein containing a caspase recruitment domain, ASC, bridges interactions between inflammasome sensors and caspase-1 to promote caspase- 1 oligomerization and the formation of a single micrometer-sized supramolecular fibril structure named the "ASC speck." ASC is essential for Pyrin and other PYD domain-containing sensors (NLRP3, AIM2) to recruit caspase-1, whereas the caspase recruitment domain-based sensors (NLRP1b and NLRC4) can also recruit caspase- 1 directly as shown by the induction of caspase-1-mediated pyroptosis and cytokine secretion from macrophages of ASC-deficient mice (Broz et al. 2010; Van Opdenbosch et al. 2014).

\section{INNATE AND ADAPTIVE IMMUNE \\ STIMULATION BY INFLAMMASOME- DEPENDENT IL-1 FAMILY CYTOKINES}

As discussed above, secreted IL- $1 \alpha$ and IL-1 $\beta$, which only share $26 \%$ homology at the protein level, are recruited to the same membranebound receptor (IL-1R), leading to similar immunological outcomes (March et al. 1985). An important difference, however, is that both fulllength and mature IL- $1 \alpha$ are able to bind IL-1R to induce signaling, while only mature IL-1 $\beta$ is able to do so (Mosley et al. 1987). IL-18 binds to IL-18R $\alpha$, which heterodimerizes with IL-18R $\beta$. Noteworthy, all IL-1 receptor family members contain a TIR domain responsible for recruitment of MyD88 and subsequent engagement of $N F-\kappa B$ and mitogen-activated protein kinase (MAPK)-dependent transcriptional reprogramming (Fig. 1) (Dinarello 2009). These receptors are differentially expressed on responder cells, enabling them to engage various facets of the immune system. Although IL- $1 \alpha$ and IL- $1 \beta$ signal through the same receptors, these cytokines are biologically not fully redundant as studies using knockout mice showed IL- $1 \alpha$ to be the predominant cytokine that promotes allergy responses and Th17 differentiation in the gut and the skin (Horai et al. 1998; Nakae et al. 2001; Chung et al. 2009). In contrast, a major role for IL-1 $\beta$ was attributed to induction of fever (Horai et al. 1998; Nakae et al. 2001; Chung et al. 2009). Apart from being a powerful endogenous pyrogen, IL- $1 \beta$ is also a potent recruiter and activator of neutrophils and macrophages. IL-1 $\beta$ is also well known to drive expression of adhesion molecules on immune cells to promote tissue infiltration of monocytes from circulation that instigate inflammatory responses (Wang et al. 1995). Additionally, lowered pain threshold, vasodilatation, and hypertension were reported to be regulated by IL- 1 signaling. A role for IL-1 in the regulation of B-cell proliferation and antibody production was also suggested through its ability to stimulate production of IL-6 (Antoni et al. 1986). Originally, IL-18 was identified as interferon (IFN)- $\gamma$-inducing factor (IGIF) given its major role in the production of IFN- $\gamma$ from T cells and natural killer (NK) cells. IL-18 was first seen as a Th1-promoting cytokine in the presence of IL- 2 costimulation. IL-18 is now also known to promote severe airway inflammation through the production of Th2 cytokines by naïve or Th1 polarized $\mathrm{T}$ cells when combined with CD3 stimulation (Nakanishi et al. 2001; Hata et al. 2004). Taken together, these results show that inflammasomedependent cytokines of the IL-1 family coordinate responses to PAMPs and DAMPs by impacting strongly on both innate and adaptive immune responses. 
Inflammasome-Dependent Cytokines in Health and Disease

\section{INFLAMMASOME-DEPENDENT IL-1 FAMILY CYTOKINES IN AUTOINFLAMMATORY DISEASES}

The above illustrates the vital role of inflammasome-released cytokines and alarmins in sustaining homeostasis. However, when signaling is deregulated, it may become detrimental to the host, as shown by the extensive catalog of human diseases involving these cytokines and alarmins. Based on progressing insight in the genetic and functional etiology of noninfectious immune diseases, primary immunodeficiencies are increasingly regarded as a clinical continuum, ranging from monogenic autoinflammatory diseases that are mainly driven by aberrant innate immune signaling to equally rare monogenic autoimmune disorders that involve predominantly the adaptive immune response (McGonagle and McDermott 2006; Masters et al. 2009). The highly prevalent diseases that affect mankind are situated somewhere along this axis, involving both immune compartments to varying degrees. Intriguingly, inflammasome-released cytokines and alarmins appear to be implicated throughout the whole spectrum from autoinflammatory to autoimmune diseases, although inflammasome signaling has so far mainly been characterized in innate immune cells. This insight coincides with a steady increase in the number of clinical studies showing the efficacy of anti-IL-1 therapies in different diseases, although the underlying mechanisms and causal connections remain unclear in most cases. In the following sections, the contribution of inflammasome-released cytokines and alarmins in autoinflammatory diseases will be discussed. The interested reader is referred to other work for more detailed discussions on their roles in autoimmunity (Shaw et al. 2011; Yang and Chiang 2015).

As introduced before, autoinflammatory diseases are defined as illnesses caused by primary dysfunction of the innate immune system, and are thus frequently marked by the absence of pathogenic autoantibodies and autoreactive $\mathrm{T}$ cells (McGonagle and McDermott 2006; Masters et al. 2009). They are sometimes also referred to as "periodic fever syndromes" because many of these diseases feature recurrent fevers and episodes of systemic or organ-specific inflammation.

A clinical challenge is that efficient diagnosis is hampered by nonspecific symptoms that are shared by patients suffering from diseases with distinct etiologies. Moreover, patients suffering from autoinflammatory diseases with similar underlying mechanisms and that respond to particular therapies, may present with atypical or even distinctive symptoms. Thus, there is a growing need for functional assays and genetic markers to classify these diseases. Although this is work in progress that needs refinement whenever new information becomes available, classification based on the predominant proinflammatory cytokine(s) or inflammatory pathways involved may be sensible. As such, one may primarily distinguish diseases caused by excessive IL-1, type I IFN, tumor necrosis factor (TNF) production, and/or NF- $\mathrm{\kappa B}$ signaling. Here, we focus on the IL-1-mediated autoinflammatory diseases (AIDs). The subset of IL-1-driven syndromes that are caused by mutations in core inflammasome proteins are further defined as "intrinsic inflammasomopathies” (Table 2). There are, however, also several diseases for which inflammasome involvement is hypothesized or in which mutations have been defined in proteins indirectly engaging inflammasome activation. They will be grouped as "extrinsic inflammasomopathies."

\section{Intrinsic Inflammasomopathies}

To date, autoinflammatory disorders caused by mutations in four out of the five well-established inflammasome sensors have been documented. Pathogenic NLRP1 mutations were shown to cause skin inflammatory and cancer susceptibility syndromes in the absence of recurring fever (Zhong et al. 2016) as well as an arthritis and dyskeratosis syndrome (Grandemange et al. 2016). Instead, mutations in NLRP3, NLRC4, and Pyrin are linked to systemic periodic fever syndromes. Caspase-1 variants also have been identified in patients suffering from recurrent systemic inflammation. Surprisingly, these CASP1 variants with reduced or even abrogated 
H. Van Gorp et al.

Table 2. Interleukin (IL)-1-mediated autoinflammatory diseases

\begin{tabular}{|c|c|c|c|c|}
\hline Disease & Gene & Mode of inheritance & Treatments & Mouse model \\
\hline \multicolumn{5}{|c|}{ Intrinsic inflammasomopathies } \\
\hline CAPS & $N L R P 3$ & Autosomal dominant & Anti-IL-1 & Nlrp3 knockin mice \\
\hline FMF & $M E F V$ & Autosomal recessive & $\begin{array}{l}\text { Colchicine, anti-IL-1 in } \\
\text { colchicine-resistent } \\
\text { patients }\end{array}$ & $\begin{array}{l}\text { Mefv knockin mice with } \\
\text { mutant human B30.2 } \\
\text { domain }\end{array}$ \\
\hline NLRC4-AID & NLRC4 & Autosomal dominant & $\begin{array}{l}\text { Anti-IL-1, -IL-18, -IFN- } \\
\gamma \text { (explorative, few } \\
\text { patients) }\end{array}$ & - \\
\hline DIRA & $I L 1 R N$ & Autosomal recessive & Anti-IL-1 & Illrn-deficient mice \\
\hline \multicolumn{5}{|c|}{ Extrinsic inflammasomopathies } \\
\hline NLRP12AD & NLRP12 & Autosomal dominant & $\begin{array}{l}\text { Anti-IL-1 (temporary } \\
\text { effect) }\end{array}$ & - \\
\hline PAPA & PSTPIP1 & Autosomal dominant & Anti-IL-1, -TNF & Pstpip1 knockin mice \\
\hline TRAPS & TNFRSF1A & Autosomal dominant & Anti-IL-1, -TNF & Tnfrsfla knockin mice \\
\hline MKD/HIDS & $M V K$ & Autosomal recessive & Anti-IL-1, -TNF & $\begin{array}{l}\text { Heterozygous } M v k- \\
\text { deficient mice }\end{array}$ \\
\hline Majeed syndrome & LPIN2 & Autosomal recessive & Anti-IL-1 & - \\
\hline
\end{tabular}

enzymatic activity nonetheless may create a proinflammatory environment that might be causal to the symptoms observed (Heymann et al. 2014). To our knowledge, however, no mutations in the inflammasome adaptor ASC have been reported to cause inflammatory disease.

\section{Cryopyrin-Associated Periodic Syndromes (CAPS)}

CAPS are a group of inherited inflammatory disorders encompassing three different phenotypes of increasing severity, namely, familial cold-induced autoinflammatory syndrome (FCAS), Muckle-Wells syndrome (MWS), and neonatal-onset multisystem inflammatory disease ([NOMID] also known as chronic infantile neurologic, cutaneous, articular [CINCA] syndrome). These disorders thus represent a spectrum of separate disease entities with overlapping clinical features of variable severity, even though sharing a common genetic cause. About 50 years after these syndromes were described, NLRP3 (CIAS1) was identified as the causal gene (Cuisset et al. 1999; Hoffman et al. 2001). More than 100 disease-causing variants in NLRP3 are currently registered in the Infevers database (Milhavet et al. 2008). Most are missense mutations in exon 3, which encodes the central NACHT domain responsible for ATP binding and hydrolysis. CAPS disease is autosomal dominant with variable penetrance, and up to $70 \%$ of CAPS patients that appear NLRP3 mutation-negative by conventional Sanger DNAsequencing methods may show somatic mosaicism for pathogenic NLRP3 mutations (Saito et al. 2008; Tanaka et al. 2011).

Mutant NLRP3 is thought to alter the balance for NLRP3 inflammasome nucleation, resulting in excessive inflammasome signaling in response to otherwise harmless environmental cues. This hypothesis is supported by the observation that cold exposure and low-dose LPS treatment of peripheral blood mononuclear cells (PBMCs) from CAPS patients trigger secretion of excessive IL- $1 \beta$ and IL-18 compared with levels of healthy controls (Janssen et al. 2004; Brydges et al. 2009). Furthermore, mouse strains harboring CAPS-associated mutations in Nlrp3 show elevated levels of IL- $1 \beta$ and IL- 18 in serum and closely mimic human disease. Also, cultured cells from Nlrp3 mutant mice are hyperrespon- 
Inflammasome-Dependent Cytokines in Health and Disease

sive to inflammatory stimuli, similar to patients (Brydges et al. 2009). To assess the relative contribution of IL-1 and IL-18 signaling in CAPS, mutant mice were bred to mice deficient for the respective cytokine receptors. Notably, although both IL-1R1 and IL-18R were implicated, caspase-1 deletion appeared more effective in controlling ongoing inflammation. This suggests that release of pyroptosis-associated alarmins such as HMGB1 might also contribute to the disease. However, therapeutic neutralization of IL-1 $\beta$ is highly effective in controlling disease activity and leads to dramatic symptomatic improvement in the majority of CAPS patients despite the cytokine being largely undetectable in circulation of CAPS patients (Goldbach-Mansky et al. 2006; Gattorno et al. 2007; Brydges et al. 2013). Altogether, this suggests that excess IL$1 \beta$ has a primary pathogenic role in CAPS disease, while additional inflammasome effector mechanisms may further support a vicious inflammatory cycle.

\section{Familial Mediterranean Fever (FMF)}

With an estimated 150,000 patients, FMF is considered the most common monogenic autoinflammatory disease worldwide. Most patients have autosomal recessive inheritance, although cases with apparent dominant disease also are relatively frequent. FMF usually has a childhood onset, and is characterized by recurrent attacks of fever associated with serositis. Its main longterm complication is amyloid A (AA) amyloidosis, a severe manifestation with poor prognosis. Since its suggested use in 1972, the microtubule polymerization inhibitor colchicine has become the gold standard for treatment in FMF, with an overall nonresponder rate of only 5\%-10\% (Goldfinger 1972; Zemer et al. 1986). Colchicine not only prevents FMF attacks, but also normalizes disease-associated complications (Zemer et al. 1986). FMF is particularly common around the Mediterranean basin, the Middle East, and the Caucasus, frequently affecting Jewish, Turkish, Armenian, Arab and Southern European, and North African populations. In these regions, the prevalence of FMF is between 1 in 500 and 1 in 1000 .
Mutations in $M E F V$ were shown to cause the disease in most FMF patients (Balow et al. 1997; French FMF Consortium 1997). To date, more than $310 \mathrm{MEFV}$ sequence variants have been reported in the Infevers database (Milhavet et al. 2008). $M E F V$ mutations are very common in Middle Eastern populations and the Mediterranean basin, with carrier rates reaching up to 1:5 individuals. This suggests an evolutionary benefit for heterozygous individuals living in these countries (Schaner et al. 2001; Fumagalli et al. 2009). Paradoxically, similar to apparently healthy individuals of the Mediterranean basin, only a single demonstrable $M E F V$ mutation is found in as many as $20 \%-30 \%$ of patients diagnosed with FMF (Booty et al. 2009; Marek-Yagel et al. 2009; Ozen 2009). Moreover, a subset of $10 \%-20 \%$ of patients lacks MEFV mutations altogether (Ben-Zvi et al. 2015). Although the disease is less prevalent in Northern Europe (with estimated frequencies below 1:75,000), the disease has spread over the world with migrations of South European, North African, and Middle Eastern populations over the past centuries and in more recent times (Ozen and Bilginer 2014).

$M E F V$ encodes Pyrin, a protein that is highly expressed in monocytes and neutrophils (Balow et al. 1997; French FMF Consortium 1997; Centola et al. 2000). Pyrin engages inflammasome activation in response to RhoA GTPaseinactivating bacterial toxins (Xu et al. 2014). Although this discovery sparked significant research in Pyrin regulation mechanisms and FMF etiology (Gao et al. 2016; Masters et al. 2016; Park et al. 2016; Van Gorp et al. 2016), the molecular mechanisms driving pathology in FMF are still poorly understood. As in most AID patients, IL-1 $\beta$ is barely detectable in the serum of FMF patients. IL-18, on the other hand, is elevated in serum of FMF patients, regardless of whether measured in patients experiencing an attack or when in remission (Haznedaroglu et al. 2005; Koga et al. 2016). These findings warrant further investigation of the potential role of IL-18 in FMF pathogenesis. Of note, mouse Pyrin lacks the carboxy-terminal B30.2 (PRY/SPRY) domain that is mutated in most FMF patients. Mice engineered to express Pyrin with a human B30.2 extension containing 
H. Van Gorp et al.

FMF-associated mutations spontaneously develop IL-1-dependent inflammation (Chae et al. 2011). In agreement, disease symptoms in approximately $2 / 3$ of FMF patients with inadequate response to colchicine were effectively treated with anti-IL-1 (Kuijk et al. 2007; Calligaris et al. 2008; Hashkes et al. 2012; van der Hilst et al. 2016).

Notably, despite the efficacious prophylactic use of colchicine in controlling FMF symptoms, FMF-associated mutations in the B30.2 domain were recently shown to dispense with the requirement for microtubules in Pyrin inflammasome activation (Van Gorp et al. 2016). Only FMF PBMCs activated the Pyrin inflammasome independently of microtubules because colchicine prevented Pyrin inflammasome activation in PBMCs of healthy individuals and patients suffering from other autoinflammatory diseases (CAPS and systemic juvenile idiopathic arthritis [sJIA]) (Van Gorp et al. 2016). The prophylactic efficacy of colchicine treatment is thus likely to be found downstream from Pyrin inflammasome activation. One likely explanation is that it may limit neutrophil recruitment into tissues by countering microtubule-dependent rolling, transmigration, and extravasation.

\section{NLRC4-Associated Autoinflammatory Diseases (NLRC4-AIDs)}

Several autoinflammatory patients were recently described with mutations in the inflammasome sensor NLRC4 (Canna et al. 2014; Kitamura et al. 2014; Romberg et al. 2014; Bracaglia et al. 2015; Kawasaki et al. 2016; Volker-Touw et al. 2016). NLRC4-AID may have a broad spectrum of clinical presentations. Patients have been reported with CAPS-like disease, or may suffer from episodic fever, enterocolitis, arthritis, cutaneous erythematous nodes, and/or urticarial rash. In some patients, NLRC4-AID may cause near-fatal autoinflammation associated with severe macrophage activation syndrome (MAS). The latter is a potentially lethal complication in rheumatic diseases associated with highly elevated ferritin and IL-18 levels in circulation. Although clinical presentation may vary considerably, all patients had an autosomal dominant inheritance of NLRC4 missense mutations (Canna et al. 2014; Kitamura et al. 2014; Romberg et al. 2014; Bracaglia et al. 2015; VolkerTouw et al. 2016). A single case with apparent de novo somatic mosaicism in NLRC4 has also been reported (Kawasaki et al. 2016). All disease-linked mutations are located within or close to the central NACHT domain. Mapping of these mutations on the crystal structure of murine NLRC4 (Hu et al. 2013) suggests that they may destabilize intramolecular interactions that keep NLRC4 in an autorepressed conformation (Canna et al. 2014). In agreement with a gain-offunction mode of operation, increased IL-18 and ferritin levels were detected in serum of several NLRC4-AID patients (Canna et al. 2014; Romberg et al. 2014; Bracaglia et al. 2015; Kawasaki et al. 2016; Volker-Touw et al. 2016). Unlike IL18 , IL-1 $\beta$ was barely detectable in circulation of these patients (Canna et al. 2014; Kawasaki et al. 2016; Volker-Touw et al. 2016).

Unlike in CAPS, clinical responses to antiIL-1 therapy appear more disparate in NLRC4AID. This is illustrated by clinical responses to anakinra-a recombinant IL-1Ra-in a large Dutch pedigree, which varied from resistance to complete remission (Volker-Touw et al. 2016). Moreover, anakinra treatment in another patient normalized some markers of systemic inflammation and enabled cessation of steroids, without affecting serum IL-18 levels (Canna et al. 2014). The above suggests that excessive IL-18 may contribute importantly to NLRC4AID pathology. In agreement, an infant with NLRC4-AID and severe MAS that was refractory to anti-TNF and anti-IL-1 $\beta$ therapy was effectively treated with recombinant human IL18BP, which binds and neutralizes bioactive IL-18 (Canna et al. 2016). IFN- $\gamma$, which is produced by $\mathrm{T}$ lymphocytes and NK cells in response to myeloid cell-derived IL-18 and IL-2, also may be a promising target for treatment of NLRC4-AID and associated MAS (Bracaglia et al. 2015). Experience from "emergency compassioned use" appears highly promising, and controlled studies therefore may expedite regulatory approval and adoption of these investigational therapeutic agents in NRC4-AID and other MAS-associated diseases. 
Inflammasome-Dependent Cytokines in Health and Disease

\section{Deficiency of the IL-1 Receptor Antagonist}

Deficiency of the IL-1 receptor antagonist (DIRA) is a very rare autosomal recessive disease caused by mutations in the IL1RN gene encoding IL-1Ra (Aksentijevich et al. 2009; Reddy et al. 2009). Pathogenic mutations result in defective IL-1Ra production, thus causing unopposed IL-1 signaling on engagement of the cognate receptor. IL-1R1 is ubiquitously expressed throughout tissues with particularly high expression levels noted in keratinocytes, possibly explaining the characteristic skin lesions and massive neutrophilic infiltration associated with the disease. DIRA is further associated with bone lesions and joint inflammation. If left untreated, DIRA presents a life-threatening condition resulting from the development of a systemic inflammatory response syndrome and death from multiorgan failure. Remarkably, however, recurrent fevers have not been reported to occur in these patients. Although lifelong treatment is required, patients respond very well to anti-IL-1 therapy.

\section{Extrinsic Inflammasomopathies}

Although intrinsic inflammasomopathies have molecular etiologies clearly tightening them to defined inflammasome signaling mechanisms as discussed above, extrinsic inflammasomopathies are disorders for which the potential link to aberrant inflammasome signaling still needs to be firmly established. As understanding of the roles of inflammasomes and IL-1 in these diseases progresses, some of these pathologies may require reclassification as intrinsic inflammasomopathies or inflammasome-independent syndromes in the future.

\section{Majeed Syndrome}

Majeed syndrome is a rare autosomal recessive disorder caused by mutations in LPIN2, a gene encoding a phosphatidic acid phosphatase (Ferguson et al. 2005). To date, 18 variants have been reported for Majeed syndrome in Infevers. Overlapping with the clinical presentation of DIRA patients, Majeed syndrome patients pre- sent with chronic recurrent multifocal osteomyelitis and neutrophilic skin lesions. Unlike DIRA, however, these symptoms are often accompanied by anemia and periodic fevers as part of the typical clinical picture of adult Majeed syndrome patients. Although the underlying molecular etiology of the disease is unclear, IL-1 likely is a key factor of pathogenesis in this syndrome as illustrated by anecdotal evidence showing a rapid and impressive clinical response to IL-1 $\beta$-blocking therapies in two siblings with Majeed syndrome (Herlin et al. 2013).

\section{NLRP12-Associated Autoinflammatory Disorder (NLRP12AD)}

Missense mutations in NLRP12 were reported to cause CAPS-like clinical manifestations (Jeru et al. 2008, 2011b; Borghini et al. 2011). To date, 35 NLRP12 variants have been reported in the Infevers database. Akin to CAPS, NLRP12AD has an autosomal dominant inheritance, and PBMCs of NLRP12AD patients also were shown to have spontaneous and cold exposure-induced IL-1 $\beta$ release (Jeru et al. 2011a). Although the role of NLRP12 in inflammasome activation and secretion of IL-1 $\beta$ remains controversial, the clinical phenotype of NLRP12AD patients combined with cold-induced IL- $1 \beta$ release by ex vivo-stimulated PBMCs provided a rationale for exploring anti-IL-1 therapy in these patients. In contrast to CAPS patients in which anti-IL-1 is highly effective, anti-IL-1 initially led to marked but incomplete clinical improvement, and patients progressively relapsed after 3 months of treatment (Jeru et al. 2011a). Although larger studies are required, these findings suggest that NLRP12AD may differ mechanistically from CAPS. Further understanding of NLRP12's roles in the immune system and the underlying mechanisms may pave the way toward more effective therapeutic options for these patients.

Pyogenic Arthritis, Pyoderma Gangrenosum, and Acne Syndrome

Pyogenic arthritis, pyoderma gangrenosum, and acne (PAPA) syndrome is an autosomal dominant disease that is characterized by painful 
H. Van Gorp et al.

flares of recurrent arthritis with predominantly neutrophilic infiltration, and variable skin inflammation (Smith et al. 2010). In most patients, the disease arises from mutations in the prolineserine-threonine phosphatase-interacting protein 1 gene (PSTPIP1, also known as CD2-binding protein 1 [CD2BP1]) (Yeon et al. 2000; Wise et al. 2002). To date, 25 disease-associated variants of PSTPIP1 have been reported in Infevers. PSTPIP1 is a cytoskeleton-associated protein with diverse binding partners, including the phosphatase rich in proline $(\mathrm{P})$, glutamic acid $(\mathrm{E})$, serine $(\mathrm{S})$, and threonine $(\mathrm{T})$ residues-type protein tyrosine phosphatase (PTP-PEST, also known as PTPN12), Wiskott-Aldrich syndrome protein (WASP), c-Abl kinase, Fas ligand, and the inflammasome protein Pyrin (Smith et al. 2010). Notably, PAPA-associated PSTPIP1 mutants show higher binding affinity for Pyrin compared with wild-type (WT) PSTPIP1 (Shoham et al. 2003), and disease-linked PSTPIP1 mutants were proposed to engage inflammasome activation through Pyrin (Yu et al. 2007; Waite et al. 2009). However, it is not clear why colchicine therapy, highly efficacious in FMF patients, does not alter disease progression in PAPA patients (Geusau et al. 2013). Nevertheless, anecdotal evidence suggests IL- $1 \beta$ blockade as a promising approach for controlling clinical manifestations in this ultrarare disease (Dierselhuis et al. 2005; Federici et al. 2013; Geusau et al. 2013), warranting further investigation in larger clinical trials.

\section{Mevalonate Kinase Deficiency/Hyper-IgD Syndrome}

In most patients, mevalonate kinase deficiency (MKD) is caused by homozygous loss-of-function mutations in the $M V K$ gene encoding mevalonate kinase, although a subset of patients has no detectable MVK mutation, and others may display dominant autosomal disease associated with a single mutation. MVK is an enzyme of the cholesterol and isoprene biosynthesis pathway (van der Meer et al. 1984; Drenth et al. 1999; Houten et al. 1999). The disease was originally named hyperimmunoglobulin D syndrome (HIDS) because constitutively high levels of immunoglobulin D (IgD) were observed in circulation of MKD patients, next to elevated levels of C-reactive protein, erythrocyte sedimentation rate, and other classical markers of ongoing inflammation. However, with the realization that not all MKD patients have increased serum IgD levels, that IgD levels do not appear to correlate with disease severity, and that elevated IgD levels are sometimes also detected in patients with other autoinflammatory diseases, the disease was renamed MKD to more accurately refer to the factor causing pathogenesis (Ammouri et al. 2007).

$\mathrm{MKD}$ is a very rare disease with currently 204 disease-associated $M V K$ variants reported in the Infevers database. Most patients are of Caucasian background, with highest disease incidence in individuals of Dutch and French descent. Depending on the level of residual MVK enzymatic activity, the clinical spectrum ranges from mild to potentially lethal forms of mevalonic aciduria. In addition to recurrent fever, MKD patients may further display skin rash, arthralgia, myalgia, and arthritis. The threshold-dependent phenotype seen in patients is also reflected in mouse models, with MVK deficiency causing embryonic lethality, and haploinsufficient mice grossly phenocopying some serological parameters of the human disease (Hager et al. 2007).

Although the molecular etiology of MKD is still debated, it is clear that reduced MVK activity leads to build-up of mevalonic acid, and a shortage of cholesterol, vitamins, and other products of the isoprenoid biosynthesis pathway, which cause uncontrolled release of IL- $1 \beta$ through incompletely understood mechanisms. An attractive hypothesis suggests that defects in the mevalonate pathway may trigger unwarranted activation of the Pyrin inflammasome consequent to defective geranylgeranylation of RhoA GTPase (Mandey et al. 2006; Akula et al. 2016; Park et al. 2016). Surprisingly, however, MKD patients generally do not benefit from colchicine therapy, although on the other hand experience with IL-1 blockade has been impressive with $\sim 90 \%$ of patients having immediate and complete clinical responses (Ter Haar et al. 2013; Jesus and Goldbach-Mansky 2014). 
Inflammasome-Dependent Cytokines in Health and Disease

TNF Receptor-Associated Periodic Syndrome (TRAPS)

TRAPS is an autosomal dominant disease caused by mutations in the TNFRSF1A gene coding for TNF receptor 1 (TNF-R1) (McDermott et al. 1999). More than 140 TRAPS-linked mutations in TNFRSF1A have been identified. TNF$\mathrm{R} 1$ is a membrane-bound member of the death receptor family that initiates signaling on binding of its ligand TNF. Activation of TNF-R1 implies the formation of two spatially distinct TNFR1 signaling complexes that have the capacity to signal either NF- $\kappa \mathrm{B}$ activation (prosurvival) or programmed cell death. Most TNFRSF1A gene mutations that cause TRAPS result in accumulation of misfolded TNF-R1, and reduced expression of the mutated receptor at the plasma membrane. Starting from TNFRSF1A heterozygosity and the dominant inheritance of the disease, analysis of knockin mice with heterozygous mutations in TNF-R1 revealed that WT and mutant TNF-R1 act in concert from distinct cellular locations to potentiate inflammation in TRAPS (Simon et al. 2010). However, although mutations in TNF-R1 are the genetic basis of the disease, long-term use of TNF-inhibiting agents has been surprisingly ineffective in the clinic, with some biologicals even precipitating inflammatory attacks and worsening disease (Jacobelli et al. 2007; Nedjai et al. 2009; Quillinan et al. 2011; Bulua et al. 2012). Contrastingly, the use of both anakinra and the IL-1 $\beta$-neutralizing monoclonal antibody canakinumab induced rapid control of symptoms in TRAPS patients with sustained clinical benefits during treatment (Simon et al. 2004; Gattorno et al. 2008, 2016; Brizi et al. 2012). Thus, although the pathogenesis of TRAPS is complex and still not completely understood, the success of anti-IL-1 therapies clearly indicates the importance of IL-1 signaling in TRAPS pathogenesis.

\section{CONCLUDING REMARKS}

As discussed above, autoinflammatory diseases may be caused by a myriad of genes regulating a diversity of innate immune and metabolic pathways. These defects converge on a select number of key inflammatory mediators, with inflamma- some-produced IL-1 $\beta$ featuring prominently in this list. This is evidenced by the therapeutic efficacy of IL-1-blocking strategies in clinically diverse-though not all-autoinflammatory diseases. More recently, inflammasome-produced IL-18 and downstream IFN- $\gamma$ production have emerged as potential therapeutic targets in the treatment of certain autoinflammatory syndromes and MAS. In addition, the existence of IL-1 $\beta /$ IL-18-independent inflammasome effector mechanisms, including pyroptosis and the associated release of alarmins such as HMGB1 and S100 proteins, highlight further avenues by which inflammasomes may contribute to autoinflammation. Undoubtedly, progressive understanding of the molecular underpinnings regulating inflammasome activation and production of the key cytokines IL-1 $\beta$ and IL-18 may provide much needed novel therapeutic targets for modulating inflammation and immunity. These endeavors should benefit patients suffering from autoinflammatory, as well as other immune-related diseases.

\section{ACKNOWLEDGMENTS}

We apologize to the authors whose work was omitted because of space limitations. We thank Dr. Lieselotte Vande Walle for help with artwork. N.V.O. is a postdoctoral fellow with the Fund for Scientific Research-Flanders. This work is supported by the European Research Council (Consolidator Grant No. 683144 and Proof-of-Concept Grant No. 727674) and the Baillet Latour Medical Research grant to M.L.

\section{REFERENCES}

\footnotetext{
Afonina IS, Tynan GA, Logue SE, Cullen SP, Bots M, Luthi AU, Reeves EP, McElvaney NG, Medema JP, Lavelle EC, et al. 2011. Granzyme B-dependent proteolysis acts as a switch to enhance the proinflammatory activity of IL- $1 \alpha$. Mol Cell 44: 265-278.

Aksentijevich I, Masters SL, Ferguson PJ, Dancey P, Frenkel J, van Royen-Kerkhoff A, Laxer R, Tedgard U, Cowen EW Pham TH, et al. 2009. An autoinflammatory disease with deficiency of the interleukin-1-receptor antagonist. $N$ Engl J Med 360: 2426-2437.

Akula MK, Shi M, Jiang Z, Foster CE, Miao D, Li AS, Zhang X, Gavin RM, Forde SD, Germain G, et al. 2016. Control of the innate immune response by the mevalonate pathway. Nat Immunol 17: 922-929.
} 
H. Van Gorp et al.

Ammouri W, Cuisset L, Rouaghe S, Rolland MO, Delpech M, Grateau G, Ravet N. 2007. Diagnostic value of serum immunoglobulinaemia D level in patients with a clinical suspicion of hyper IgD syndrome. Rheumatology (Oxford) 46: 1597-1600.

Antoni G, Presentini R, Perin F, Tagliabue A, Ghiara P, Censini S, Volpini G, Villa L, Boraschi D. 1986. A short synthetic peptide fragment of human interleukin 1 with immunostimulatory but not inflammatory activity. J Immunol 137: 3201-3204.

Balow JE Jr, Shelton DA, Orsborn A, Mangelsdorf M, Aksentijevich I, Blake T, Sood R, Gardner D, Liu R, Pras E, et al. 1997. A high-resolution genetic map of the familial Mediterranean fever candidate region allows identification of haplotype-sharing among ethnic groups. Genomics 44: 280-291.

Bauernfeind FG, Horvath G, Stutz A, Alnemri ES, MacDonald K, Speert D, Fernandes-Alnemri T, Wu J, Monks BG, Fitzgerald KA, et al. 2009. Cutting edge: NF- $\mathrm{kB}$ activating pattern recognition and cytokine receptors license NLRP3 inflammasome activation by regulating NLRP3 expression. J Immunol 183: 787-791.

Ben-Zvi I, Herskovizh C, Kukuy O, Kassel Y, Grossman C, Livneh A. 2015. Familial Mediterranean fever without $M E F V$ mutations: A case-control study. Orphanet $J$ Rare Dis 10: 34 .

Booty MG, Chae JJ, Masters SL, Remmers EF, Barham B, Le JM, Barron KS, Holland SM, Kastner DL, Aksentijevich I. 2009. Familial Mediterranean fever with a single $M E F V$ mutation: Where is the second hit? Arthritis Rheum 60: 1851-1861.

Boraschi D, Lucchesi D, Hainzl S, Leitner M, Maier E, Mangelberger D, Oostingh GJ, Pfaller T, Pixner C, Posselt G, et al. 2011. IL-37: A new anti-inflammatory cytokine of the IL-1 family. Eur Cytokine Netw 22: 127-147.

Borghini S, Tassi S, Chiesa S, Caroli F, Carta S, Caorsi R, Fiore M, Delfino L, Lasiglie D, Ferraris C, et al. 2011. Clinical presentation and pathogenesis of cold-induced autoinflammatory disease in a family with recurrence of an NLRP12 mutation. Arthritis Rheum 63: 830-839.

Boyden ED, Dietrich WF. 2006. Nalp1b controls mouse macrophage susceptibility to anthrax lethal toxin. Nat Genet 38: 240-244.

Bracaglia C, Gatto A, Pardeo M, Lapeyre G, Ferlin W, Nelson R, de Min C, De Benedetti F. 2015. Anti interferon- $\gamma$ (IFN $\gamma)$ monoclonal antibody treatment in a patient carrying an NLRC4 mutation and severe hemophagocytic lymphohistiocytosis. Pediatr Rheumatol 13: 1-2.

Brizi MG, Galeazzi M, Lucherini OM, Cantarini L, Cimaz R. 2012. Successful treatment of tumor necrosis factor receptor-associated periodic syndrome with canakinumab. Ann Intern Med 156: 907-908.

Broz P, von Moltke J, Jones JW, Vance RE, Monack DM. 2010. Differential requirement for caspase- 1 autoproteolysis in pathogen-induced cell death and cytokine processing. Cell Host Microbe 8: 471-483.

Brydges SD, Mueller JL, McGeough MD, Pena CA, Misaghi A, Gandhi C, Putnam CD, Boyle DL, Firestein GS, Horner AA, et al. 2009. Inflammasome-mediated disease animal models reveal roles for innate but not adaptive immunity. Immunity 30: 875-887.
Brydges SD, Broderick L, McGeough MD, Pena CA, Mueller JL, Hoffman HM. 2013. Divergence of IL-1, IL-18, and cell death in NLRP3 inflammasomopathies. J Clin Invest 123: 4695-4705.

Bulua AC, Mogul DB, Aksentijevich I, Singh H, He DY, Muenz LR, Ward MM, Yarboro CH, Kastner DL, Siegel RM, et al. 2012. Efficacy of etanercept in the tumor necrosis factor receptor-associated periodic syndrome: A prospective, open-label, dose-escalation study. Arthritis Rheum 64: 908-913.

Calligaris L, Marchetti F, Tommasini A, Ventura A. 2008. The efficacy of anakinra in an adolescent with colchicineresistant familial Mediterranean fever. Eur J Pediatr 167: 695-696.

Canna SW, de Jesus AA, Gouni S, Brooks SR, Marrero B, Liu Y, DiMattia MA, Zaal KJ, Sanchez GA, Kim H, et al. 2014 An activating NLRC4 inflammasome mutation causes autoinflammation with recurrent macrophage activation syndrome. Nat Genet 46: 1140-1146.

Canna SW, Girard C, Malle L, de Jesus A, Romberg N, Kelsen J, Surrey LF, Russo P, Sleight A, Schiffrin E, et al. 2016. Life-threatening NLRC4-associated hyperinflammation successfully treated with IL-18 inhibition. J Allergy Clin Immunol 139: 1698-1701.

Centola M, Wood G, Frucht DM, Galon J, Aringer M, Farrell C, Kingma DW, Horwitz ME, Mansfield E, Holland SM et al. 2000. The gene for familial Mediterranean fever, $M E F V$, is expressed in early leukocyte development and is regulated in response to inflammatory mediators. Blood 95: 3223-3231.

Chae JJ, Cho YH, Lee GS, Cheng J, Liu PP, Feigenbaum L, Katz SI, Kastner DL. 2011. Gain-of-function pyrin mutations induce NLRP3 protein-independent interleukin-1 $\beta$ activation and severe autoinflammation in mice. Immunity 34: 755-768.

Choubey D. 2012. DNA-responsive inflammasomes and their regulators in autoimmunity. Clin Immunol 142: 223-231.

Chung Y, Chang SH, Martinez GJ, Yang XO, Nurieva R, Kang HS, Ma L, Watowich SS, Jetten AM, Tian Q, et al 2009. Critical regulation of early Th17 cell differentiation by interleukin-1 signaling. Immunity 30: 576-587.

Corbaz A, ten Hove T, Herren S, Graber P, Schwartsburd B, Belzer I, Harrison J, Plitz T, Kosco-Vilbois MH, Kim SH, et al. 2002. IL-18-binding protein expression by endothelial cells and macrophages is up-regulated during active Crohn's disease. J Immunol 168: 3608-3616.

Cuisset L, Drenth JP, Berthelot JM, Meyrier A, Vaudour G, Watts RA, Scott DG, Nicholls A, Pavek S, Vasseur C, et al 1999. Genetic linkage of the Muckle-Wells syndrome to chromosome 1q44. Am J Hum Genet 65: 1054-1059.

Dierselhuis MP, Frenkel J, Wulffraat NM, Boelens JJ. 2005. Anakinra for flares of pyogenic arthritis in PAPA syndrome. Rheumatology (Oxford) 44: 406-408.

Di Micco A, Frera G, Lugrin J, Jamilloux Y, Hsu ET, Tardivel A, De Gassart A, Zaffalon L, Bujisic B, Siegert S, et al. 2016. AIM2 inflammasome is activated by pharmacological disruption of nuclear envelope integrity. Proc Natl Acad Sci 113: E4671-E4680.

Dinarello CA. 1996. Biologic basis for interleukin-1 in disease. Blood 87: 2095-2147. 
Dinarello CA. 2009. Immunological and inflammatory functions of the interleukin-1 family. Annu Rev Immunol 27: 519-550.

Dinarello CA, Novick D, Kim S, Kaplanski G. 2013. Interleukin-18 and IL-18 binding protein. Front Immunol 4: 289.

Drenth JP, Cuisset L, Grateau G, Vasseur C, van de VeldeVisser SD, de Jong JG, Beckmann JS, van der Meer JW, Delpech M. 1999. Mutations in the gene encoding mevalonate kinase cause hyper-IgD and periodic fever syndrome. International Hyper-IgD Study Group. Nat Genet 22: $178-181$.

Dripps DJ, Brandhuber BJ, Thompson RC, Eisenberg SP. 1991. Interleukin-1 (IL-1) receptor antagonist binds to the $80-\mathrm{kDa}$ IL-1 receptor but does not initiate IL-1 signal transduction. J Biol Chem 266: 10331-10336.

Federici S, Martini A, Gattorno M. 2013. The central role of anti-IL-1 blockade in the treatment of monogenic and multi-factorial autoinflammatory diseases. Front Immunol 4: 351.

Ferguson PJ, Chen S, Tayeh MK, Ochoa L, Leal SM, Pelet A, Munnich A, Lyonnet S, Majeed HA, El-Shanti H. 2005. Homozygous mutations in LPIN2 are responsible for the syndrome of chronic recurrent multifocal osteomyelitis and congenital dyserythropoietic anaemia (Majeed syndrome). J Med Genet 42: 551-557.

Fernandes-Alnemri T, Yu JW, Datta P, Wu J, Alnemri ES. 2009. AIM2 activates the inflammasome and cell death in response to cytoplasmic DNA. Nature 458: 509-513.

Fernandes-Alnemri T, Yu JW, Juliana C, Solorzano L, Kang S, Wu J, Datta P, McCormick M, Huang L, McDermott E, et al. 2010. The AIM2 inflammasome is critical for innate immunity to Francisella tularensis. Nat Immunol 11:385393.

French FMF Consortium. 1997. A candidate gene for familial Mediterranean fever. Nat Genet 17: 25-31.

Fumagalli M, Cagliani R, Pozzoli U, Riva S, Comi GP, Menozzi G, Bresolin N, Sironi M. 2009. A population genetics study of the familial Mediterranean fever gene: Evidence of balancing selection under an overdominance regime. Genes Immun 10: 678-686.

Gabay C, Lamacchia C, Palmer G. 2010. IL-1 pathways in inflammation and human diseases. Nat Rev Rheumatol 6: 232-241.

Gao W, Yang J, Liu W, Wang Y, Shao F. 2016. Site-specific phosphorylation and microtubule dynamics control Pyrin inflammasome activation. Proc Natl Acad Sci 113: E4857-4866.

Gattorno M, Tassi S, Carta S, Delfino L, Ferlito F, Pelagatt MA, D'Osualdo A, Buoncompagni A, Alpigiani MG, Alessio M, et al. 2007. Pattern of interleukin-1 $\beta$ secretion in response to lipopolysaccharide and ATP before and after interleukin-1 blockade in patients with CIAS1 mutations. Arthritis Rheum 56: 3138-3148.

Gattorno M, Pelagatti MA, Meini A, Obici L, Barcellona R, Federici S, Buoncompagni A, Plebani A, Merlini G, Martini A. 2008. Persistent efficacy of anakinra in patients with tumor necrosis factor receptor-associated periodic syndrome. Arthritis Rheum 58: 1516-1520.

Gattorno M, Obici L, Cattalini M, Tormey V, Abrams K, Davis N, Speziale A, Bhansali SG, Martini A, Lachmann HJ. 2016. Canakinumab treatment for patients with active recurrent or chronic TNF receptor-associated periodic syndrome (TRAPS): An open-label, phase II study. Ann Rheum Dis 76: 173-178.

Geusau A, Mothes-Luksch N, Nahavandi H, Pickl WF, Wise CA, Pourpak Z, Ponweiser E, Eckhart L, Sunder-Plassmann R. 2013. Identification of a homozygous PSTPIP1 mutation in a patient with a PAPA-like syndrome responding to canakinumab treatment. JAMA Dermatol 149: 209-215.

Ghayur T, Banerjee S, Hugunin M, Butler D, Herzog L, Carter A, Quintal L, Sekut L, Talanian R, Paskind M, et al. 1997. Caspase- 1 processes IFN- $\gamma$-inducing factor and regulates LPS-induced IFN- $\gamma$ production. Nature 386: 619-623.

Goldbach-Mansky R, Dailey NJ, Canna SW, Gelabert A, Jones J, Rubin BI, Kim HJ, Brewer C, Zalewski C, Wiggs E, et al. 2006. Neonatal-onset multisystem inflammatory disease responsive to interleukin-1 $\beta$ inhibition. $N$ Engl J Med 355: 581-592.

Goldfinger SE. 1972. Colchicine for familial Mediterranean fever. N Engl J Med 287: 1302.

Grandemange S, Sanchez E, Louis-Plence P, Tran Mau-Them F, Bessis D, Coubes C, Frouin E, Seyger M, Girard M, Puechberty J, et al. 2016. A new autoinflammatory and autoimmune syndrome associated with NLRP1 mutations: NAIAD (NLRP1-associated autoinflammation with arthritis and dyskeratosis). Ann Rheum Dis 76: 1191-1198.

Gu Y, Kuida K, Tsutsui H, Ku G, Hsiao K, Fleming MA, Hayashi N, Higashino K, Okamura H, Nakanishi K, et al. 1997. Activation of interferon $-\gamma$ inducing factor mediated by interleukin- $1 \beta$ converting enzyme. Science 275: 206209.

Hager EJ, Tse HM, Piganelli JD, Gupta M, Baetscher M, Tse TE, Pappu AS, Steiner RD, Hoffmann GF, Gibson KM. 2007. Deletion of a single mevalonate kinase (Mvk) allele yields a murine model of hyper-IgD syndrome. J Inherit Metab Dis 30: 888-895.

Halle A, Hornung V, Petzold GC, Stewart CR, Monks BG, Reinheckel T, Fitzgerald KA, Latz E, Moore KJ, Golenbock DT. 2008. The NALP3 inflammasome is involved in the innate immune response to amyloid- $\beta$. Nat Immunol 9: 857-865.

Hashkes PJ, Spalding SJ, Giannini EH, Huang B, Johnson A, Park G, Barron KS, Weisman MH, Pashinian N, Reiff AO, et al. 2012. Rilonacept for colchicine-resistant or -intolerant familial Mediterranean fever: A randomized trial. Ann Intern Med 157: 533-541.

Hata H, Yoshimoto T, Hayashi N, Hada T, Nakanishi K. 2004. IL-18 together with anti-CD3 antibody induces human Th1 cells to produce Th1- and Th2-cytokines and IL-8. Int Immunol 16: 1733-1739.

Haznedaroglu S, Ozturk MA, Sancak B, Goker B, Onat AM, Bukan N, Ertenli I, Kiraz S, Calguneri M. 2005. Serum interleukin 17 and interleukin 18 levels in familial Mediterranean fever. Clin Exp Rheumatol 23: S77-S80.

Herlin T, Fiirgaard B, Bjerre M, Kerndrup G, Hasle H, Bing X, Ferguson PJ. 2013. Efficacy of anti-IL-1 treatment in Majeed syndrome. Ann Rheum Dis 72: 410-413.

Heymann MC, Winkler S, Luksch H, Flecks S, Franke M, Russ S, Ozen S, Yilmaz E, Klein C, Kallinich T, et al. 2014. Human procaspase-1 variants with decreased enzymatic activity are associated with febrile episodes and may con- 
H. Van Gorp et al.

tribute to inflammation via RIP2 and NF- $\mathrm{KB}$ signaling. $J$ Immunol 192: 4379-4385.

Hoffman HM, Mueller JL, Broide DH, Wanderer AA, Kolodner RD. 2001. Mutation of a new gene encoding a putative pyrin-like protein causes familial cold autoinflammatory syndrome and Muckle-Wells syndrome. Nat Genet 29: 301-305.

Horai R, Asano M, Sudo K, Kanuka H, Suzuki M, Nishihara M, Takahashi M, Iwakura Y. 1998. Production of mice deficient in genes for interleukin (IL)- $1 \alpha, \mathrm{IL}-1 \beta, \mathrm{IL}-1 \alpha / \beta$, and IL- 1 receptor antagonist shows that IL- $1 \beta$ is crucial in turpentine-induced fever development and glucocorticoid secretion. J Exp Med 187: 1463-1475.

Hornung V, Bauernfeind F, Halle A, Samstad EO, Kono H, Rock KL, Fitzgerald KA, Latz E. 2008. Silica crystals and aluminum salts activate the NALP3 inflammasome through phagosomal destabilization. Nat Immunol 9: 847-856.

Houten SM, Kuis W, Duran M, de Koning TJ, van RoyenKerkhof A, Romeijn GJ, Frenkel J, Dorland L, de Barse MM, Huijbers WA, et al. 1999. Mutations in MVK, encoding mevalonate kinase, cause hyperimmunoglobulinaemia $\mathrm{D}$ and periodic fever syndrome. Nat Genet 22: 175-177.

Howard AD, Kostura MJ, Thornberry N, Ding GJ, Limjuco G, Weidner J, Salley JP, Hogquist KA, Chaplin DD, Mumford RA, et al. 1991. IL-1-converting enzyme requires aspartic acid residues for processing of the IL- $1 \beta$ precursor at two distinct sites and does not cleave $31-\mathrm{kDa}$ IL-1 $\alpha$. J Immunol 147: 2964-2969.

Hu Z, Yan C, Liu P, Huang Z, Ma R, Zhang C, Wang R, Zhang Y, Martinon F, Miao D, et al. 2013. Crystal structure of NLRC4 reveals its autoinhibition mechanism. Science 341: 172-175.

Hu B, Jin C, Li HB, Tong J, Ouyang X, Cetinbas NM, Zhu S, Strowig T, Lam FC, Zhao C, et al. 2016. The DNA-sensing AIM2 inflammasome controls radiation-induced cell death and tissue injury. Science 354: 765-768.

Jacobelli S, Andre M, Alexandra JF, Dode C, Papo T. 2007 Failure of anti-TNF therapy in TNF receptor 1-associated periodic syndrome (TRAPS). Rheumatology (Oxford) 46: 1211-1212.

Janssen R, Verhard E, Lankester A, Ten Cate R, van Dissel JT. 2004. Enhanced interleukin- $1 \beta$ and interleukin- 18 release in a patient with chronic infantile neurologic, cutaneous, articular syndrome. Arthritis Rheum 50: 3329-3333.

Jeru I, Duquesnoy P, Fernandes-Alnemri T, Cochet E, Yu JW, Lackmy-Port-Lis M, Grimprel E, Landman-Parker J, Hentgen V, Marlin S, et al. 2008. Mutations in NALP12 cause hereditary periodic fever syndromes. Proc Natl Acad Sci 105: 1614-1619.

Jeru I, Hentgen V, Normand S, Duquesnoy P, Cochet E, Delwail A, Grateau G, Marlin S, Amselem S, Lecron JC. 2011a. Role of interleukin-1 $\beta$ in NLRP12-associated autoinflammatory disorders and resistance to anti-interleukin-1 therapy. Arthritis Rheum 63: 2142-2148.

Jeru I, Le Borgne G, Cochet E, Hayrapetyan H, Duquesnoy P, Grateau G, Morali A, Sarkisian T, Amselem S. 2011b. Identification and functional consequences of a recurrent NLRP12 missense mutation in periodic fever syndromes. Arthritis Rheum 63: 1459-1464.

Jesus AA, Goldbach-Mansky R. 2014. IL-1 blockade in autoinflammatory syndromes. Annu Rev Med 65: 223-244.
Jin T, Perry A, Jiang J, Smith P, Curry JA, Unterholzner L Jiang Z, Horvath G, Rathinam VA, Johnstone RW, et al. 2012. Structures of the HIN domain:DNA complexes reveal ligand binding and activation mechanisms of the AIM2 inflammasome and IFI16 receptor. Immunity 36: 561-571.

Kawasaki Y, Oda H, Ito J, Niwa A, Tanaka T, Hijikata A, Seki R, Nagahashi A, Osawa M, Asaka I, et al. 2016. Identification of a high-frequency somatic NLRC4 mutation as a cause of autoinflammation by pluripotent cell-based phenotype dissection. Arthritis Rheumatol 69: 447-459.

Kayagaki N, Warming S, Lamkanfi M, Vande Walle L, Louie S, Dong J, Newton K, Qu Y, Liu J, Heldens S, et al. 2011. Non-canonical inflammasome activation targets caspase11. Nature 479: 117-121.

Kim S, Bauernfeind F, Ablasser A, Hartmann G, Fitzgerald KA, Latz E, Hornung V. 2010. Listeria monocytogenes is sensed by the NLRP3 and AIM2 inflammasome. Eur $J$ Immunol 40: 1545-1551.

Kitamura A, Sasaki Y, Abe T, Kano H, Yasutomo K. 2014. An inherited mutation in NLRC4 causes autoinflammation in human and mice. J Exp Med 211: 2385-2396.

Kleiner G, Marcuzzi A, Zanin V, Monasta L, Zauli G. 2013. Cytokine levels in the serum of healthy subjects. Mediators Inflamm 2013: 434010.

Koga T, Migita K, Sato S, Umeda M, Nonaka F, Kawashiri SY, Iwamoto N, Ichinose K, Tamai M, Nakamura H, et al. 2016. Multiple serum cytokine profiling to identify combinational diagnostic biomarkers in attacks of familial Mediterranean fever. Medicine (Baltimore) 95: e3449.

Kuijk LM, Govers AM, Frenkel J, Hofhuis WJ. 2007. Effective treatment of a colchicine-resistant familial Mediterranean fever patient with anakinra. Ann Rheum Dis 66: 1545-1546.

Lachmann HJ, Lowe P, Felix SD, Rordorf C, Leslie K, Madhoo S, Wittkowski H, Bek S, Hartmann N, Bosset S, et al 2009. In vivo regulation of interleukin $1 \beta$ in patients with cryopyrin-associated periodic syndromes. J Exp Med 206: 1029-1036.

Lefrancais E, Roga S, Gautier V, Gonzalez-de-Peredo A, Monsarrat B, Girard JP, Cayrol C. 2012. IL-33 is processed into mature bioactive forms by neutrophil elastase and cathepsin G. Proc Natl Acad Sci 109: 1673-1678.

Lightfield KL, Persson J, Trinidad NJ, Brubaker SW, Kofoed EM, Sauer JD, Dunipace EA, Warren SE, Miao EA, Vance RE. 2011. Differential requirements for NAIP5 in activation of the NLRC4 inflammasome. Infect Immun 79: 1606-1614.

Lin H, Ho AS, Haley-Vicente D, Zhang J, Bernal-Fussell J, Pace AM, Hansen D, Schweighofer K, Mize NK, Ford JE. 2001. Cloning and characterization of IL-1HY2, a novel interleukin-1 family member. J Biol Chem 276: 2059720602.

Mandey SH, Kuijk LM, Frenkel J, Waterham HR. 2006. A role for geranylgeranylation in interleukin- $1 \beta$ secretion. Arthritis Rheum 54: 3690-3695.

March CJ, Mosley B, Larsen A, Cerretti DP, Braedt G, Price V, Gillis S, Henney CS, Kronheim SR, Grabstein K, et al. 1985. Cloning, sequence and expression of two distinct human interleukin-1 complementary DNAs. Nature 315: 641-647. 
Marek-Yagel D, Berkun Y, Padeh S, Abu A, Reznik-Wolf H, Livneh A, Pras M, Pras E. 2009. Clinical disease among patients heterozygous for familial Mediterranean fever. Arthritis Rheum 60: 1862-1866.

Mariathasan S, Newton K, Monack DM, Vucic D, French DM, Lee WP, Roose-Girma M, Erickson S, Dixit VM. 2004. Differential activation of the inflammasome by caspase-1 adaptors ASC and Ipaf. Nature 430: 213-218.

Mariathasan S, Weiss DS, Newton K, McBride J, O’Rourke K, Roose-Girma M, Lee WP, Weinrauch Y, Monack DM, Dixit VM. 2006. Cryopyrin activates the inflammasome in response to toxins and ATP. Nature 440: 228-232.

Martinon F, Petrilli V, Mayor A, Tardivel A, Tschopp J. 2006. Gout-associated uric acid crystals activate the NALP3 inflammasome. Nature 440: 237-241.

Masters SL, Simon A, Aksentijevich I, Kastner DL. 2009. Horror autoinflammaticus: The molecular pathophysiology of autoinflammatory disease. Annu Rev Immunol 27: 621-668.

Masters SL, Gerlic M, Metcalf D, Preston S, Pellegrini M, O'Donnell JA, McArthur K, Baldwin TM, Chevrier S, Nowell CJ, et al. 2012. NLRP1 inflammasome activation induces pyroptosis of hematopoietic progenitor cells. Immunity 37: 1009-1023.

Masters SL, Lagou V, Jeru I, Baker PJ, Van Eyck L, Parry DA, Lawless D, De Nardo D, Garcia-Perez JE, Dagley LF, et al. 2016. Familial autoinflammation with neutrophilic dermatosis reveals a regulatory mechanism of pyrin activation. Sci Transl Med 8: 332ra345.

Matusiak M, Van Opdenbosch N, Vande Walle L, Sirard JC, Kanneganti TD, Lamkanfi M. 2015. Flagellin-induced NLRC4 phosphorylation primes the inflammasome for activation by NAIP5. Proc Natl Acad Sci 112: 1541-1546.

McDermott MF, Aksentijevich I, Galon J, McDermott EM, Ogunkolade BW, Centola M, Mansfield E, Gadina M, Karenko L, Pettersson T, et al. 1999. Germline mutations in the extracellular domains of the $55 \mathrm{kDa}$ TNF receptor, TNFR1, define a family of dominantly inherited autoinflammatory syndromes. Cell 97: 133-144.

McGonagle D, McDermott MF. 2006. A proposed classification of the immunological diseases. PLoS Med 3: e297.

McMahan CJ, Slack JL, Mosley B, Cosman D, Lupton SD, Brunton LL, Grubin CE, Wignall JM, Jenkins NA, Brannan CI, et al. 1991. A novel IL-1 receptor, cloned from B cells by mammalian expression, is expressed in many cell types. EMBO J 10: 2821-2832.

Milhavet F, Cuisset L, Hoffman HM, Slim R, El-Shanti H, Aksentijevich I, Lesage S, Waterham H, Wise C, Sarrauste de Menthiere C, et al. 2008. The Infevers autoinflammatory mutation online registry: Update with new genes and functions. Hum Mutat 29: 803-808.

Mosley B, Urdal DL, Prickett KS, Larsen A, Cosman D, Conlon PJ, Gillis S, Dower SK. 1987. The interleukin-1 receptor binds the human interleukin-1 $\alpha$ precursor but not the interleukin-1 $\beta$ precursor. J Biol Chem 262: 29412944.

Nakae S, Naruse-Nakajima C, Sudo K, Horai R, Asano M, Iwakura Y. 2001. IL- $1 \alpha$, but not IL-1 $\beta$, is required for contact-allergen-specific $\mathrm{T}$ cell activation during the sensitization phase in contact hypersensitivity. Int Immunol 13: 1471-1478.
Nakanishi K, Yoshimoto T, Tsutsui H, Okamura H. 2001. Interleukin-18 regulates both Th1 and Th2 responses. Annu Rev Immunol 19: 423-474.

Nedjai B, Hitman GA, Quillinan N, Coughlan RJ, Church L, McDermott MF, Turner MD. 2009. Proinflammatory action of the antiinflammatory drug infliximab in tumor necrosis factor receptor-associated periodic syndrome. Arthritis Rheum 60: 619-625.

Netea MG, van de Veerdonk FL, van der Meer JW, Dinarello CA, Joosten LA. 2015. Inflammasome-independent regulation of IL-1-family cytokines. Annu Rev Immunol 33: 49-77.

Novick D, Kim SH, Fantuzzi G, Reznikov LL, Dinarello CA, Rubinstein M. 1999. Interleukin-18 binding protein: A novel modulator of the Th1 cytokine response. Immunity 10: $127-136$.

Ozen S. 2009. Changing concepts in familial Mediterranean fever: Is it possible to have an autosomal-recessive disease with only one mutation? Arthritis Rheum 60: 1575-1577.

Ozen S, Bilginer Y. 2014. A clinical guide to autoinflammatory diseases: Familial Mediterranean fever and next-ofkin. Nat Rev Rheumatol 10: 135-147.

Palomo J, Dietrich D, Martin P, Palmer G, Gabay C. 2015. The interleukin (IL)-1 cytokine family-Balance between agonists and antagonists in inflammatory diseases. Cytokine 76: 25-37.

Park YH, Wood G, Kastner DL, Chae JJ. 2016. Pyrin inflammasome activation and RhoA signaling in the autoinflammatory diseases FMF and HIDS. Nat Immunol 17: 914-921.

Qu Y, Misaghi S, Izrael-Tomasevic A, Newton K, Gilmour LL, Lamkanfi M, Louie S, Kayagaki N, Liu J, Komuves L, et al. 2012. Phosphorylation of NLRC4 is critical for inflammasome activation. Nature 490: 539-542.

Quillinan N, Mannion G, Mohammad A, Coughlan R, Dickie LJ, McDermott MF, McGonagle D. 2011. Failure of sustained response to etanercept and refractoriness to anakinra in patients with T50M TNF-receptor-associated periodic syndrome. Ann Rheum Dis 70: 1692-1693.

Rathinam VA, Jiang Z, Waggoner SN, Sharma S, Cole LE, Waggoner L, Vanaja SK, Monks BG, Ganesan S, Latz E, et al. 2010. The AIM2 inflammasome is essential for host defense against cytosolic bacteria and DNA viruses. Nat Immunol 11: 395-402.

Reddy S, Jia S, Geoffrey R, Lorier R, Suchi M, Broeckel U, Hessner MJ, Verbsky J. 2009. An autoinflammatory disease due to homozygous deletion of the IL1RN locus. $N$ Engl J Med 360: 2438-2444.

Romberg N, Al Moussawi K, Nelson-Williams C, Stiegler AL, Loring E, Choi M, Overton J, Meffre E, Khokha MK, Huttner AJ, et al. 2014. Mutation of NLRC4 causes a syndrome of enterocolitis and autoinflammation. Nat Genet 46: 1135-1139.

Saito M, Nishikomori R, Kambe N, Fujisawa A, Tanizaki H, Takeichi K, Imagawa T, Iehara T, Takada H, Matsubayashi T, et al. 2008. Disease-associated CIAS1 mutations induce monocyte death, revealing low-level mosaicism in mutation-negative cryopyrin-associated periodic syndrome patients. Blood 111: 2132-2141.

Sauer JD, Witte CE, Zemansky J, Hanson B, Lauer P, Portnoy DA. 2010. Listeria monocytogenes triggers AIM2-medi- 
H. Van Gorp et al.

ated pyroptosis upon infrequent bacteriolysis in the macrophage cytosol. Cell Host Microbe 7: 412-419.

Schaner P, Richards N, Wadhwa A, Aksentijevich I, Kastner D, Tucker P, Gumucio D. 2001. Episodic evolution of pyrin in primates: Human mutations recapitulate ancestral amino acid states. Nat Genet 27: 318-321.

Schreuder H, Tardif C, Trump-Kallmeyer S, Soffientini A, Sarubbi E, Akeson A, Bowlin T, Yanofsky S, Barrett RW. 1997. A new cytokine-receptor binding mode revealed by the crystal structure of the IL-1 receptor with an antagonist. Nature 386: 194-200.

Sharma S, Kulk N, Nold MF, Graf R, Kim SH, Reinhardt D, Dinarello CA, Bufler P. 2008. The IL-1 family member 7b translocates to the nucleus and down-regulates proinflammatory cytokines. J Immunol 180: 5477-5482.

Shaw PJ, McDermott MF, Kanneganti TD. 2011. Inflammasomes and autoimmunity. Trends Mol Med 17: 57-64.

Shi J, Zhao Y, Wang Y, Gao W, Ding J, Li P, Hu L, Shao F. 2014. Inflammatory caspases are innate immune receptors for intracellular LPS. Nature 514: 187-192.

Shoham NG, Centola M, Mansfield E, Hull KM, Wood G, Wise CA, Kastner DL. 2003. Pyrin binds the PSTPIP1/ CD2BP1 protein, defining familial Mediterranean fever and PAPA syndrome as disorders in the same pathway. Proc Natl Acad Sci 100: 13501-13506.

Simon A, Bodar EJ, van der Hilst JC, van der Meer JW, Fiselier TJ, Cuppen MP, Drenth JP. 2004. Beneficial response to interleukin 1 receptor antagonist in traps. Am J Med 117: 208-210.

Simon A, Park H, Maddipati R, Lobito AA, Bulua AC, Jackson AJ, Chae JJ, Ettinger R, de Koning HD, Cruz AC, et al. 2010. Concerted action of wild-type and mutant TNF receptors enhances inflammation in TNF receptor 1-associated periodic fever syndrome. Proc Natl Acad Sci 107: 9801-9806.

Smith DE, Hanna R, Della F, Moore H, Chen H, Farese AM, MacVittie TJ, Virca GD, Sims JE. 2003. The soluble form of IL-1 receptor accessory protein enhances the ability of soluble type II IL-1 receptor to inhibit IL-1 action. Immunity 18: 87-96.

Smith EJ, Allantaz F, Bennett L, Zhang D, Gao X, Wood G, Kastner DL, Punaro M, Aksentijevich I, Pascual V, et al. 2010. Clinical, molecular, and genetic characteristics of PAPA Syndrome: A review. Curr Genomics 11: 519-527.

Tanaka N, Izawa K, Saito MK, Sakuma M, Oshima K, Ohara O, Nishikomori R, Morimoto T, Kambe N, GoldbachMansky R, et al. 2011. High incidence of NLRP3 somatic mosaicism in patients with chronic infantile neurologic, cutaneous, articular syndrome: Results of an International Multicenter Collaborative Study. Arthritis Rheum 63: 3625-3632.

Taylor SL, Renshaw BR, Garka KE, Smith DE, Sims JE. 2002. Genomic organization of the interleukin-1 locus. Genomics 79: 726-733.

Ter Haar N, Lachmann H, Ozen S, Woo P, Uziel Y, Modesto C, Kone-Paut I, Cantarini L, Insalaco A, Neven B, et al. 2013. Treatment of autoinflammatory diseases: Results from the Eurofever Registry and a literature review. Ann Rheum Dis 72: 678-685.

van der Hilst J, Moutschen M, Messiaen PE, Lauwerys BR, Vanderschueren S. 2016. Efficacy of anti-IL-1 treatment in familial Mediterranean fever: A systematic review of the literature. Biologics 10: 75-80.

van der Meer JW, Vossen JM, Radl J, van Nieuwkoop JA, Meyer CJ, Lobatto S, van Furth R. 1984. Hyperimmunoglobulinaemia D and periodic fever: A new syndrome. Lancet 1: 1087-1090.

Van Gorp H, Saavedraa PHV, de Vasconcelosa NM, Van Opdenbosch N, Vande Walle L, Matusiak M, Prencipe G, Insalaco A, Van Hauwermeiren F, Demon D, et al. 2016. Familial Mediterranean fever mutations lift the obligatory requirement for microtubules in Pyrin inflammasome activation. Proc Natl Acad Sci 113: 14384-14389.

Van Opdenbosch N, Gurung P, Vande Walle L, Fossoul A, Kanneganti TD, Lamkanfi M. 2014. Activation of the NLRP1b inflammasome independently of ASC-mediated caspase-1 autoproteolysis and speck formation. Nat Commun 5: 3209.

Volker-Touw CM, de Koning HD, Giltay J, de Kovel C, van Kempen TS, Oberndorff K, Boes M, van Steensel MA, van Well GT, Blokx WA, et al. 2016. Erythematous nodes, urticarial rash and arthralgias in a large pedigree with NLRC4-related autoinflammatory disease, expansion of the phenotype. Br J Dermatol 176: 244-248.

Waite AL, Schaner P, Richards N, Balci-Peynircioglu B, Masters SL, Brydges SD, Fox M, Hong A, Yilmaz E, Kastner DL, et al. 2009. Pyrin modulates the intracellular distribution of PSTPIP1. PLoS ONE 4: e6147.

Wang X, Feuerstein GZ, Gu JL, Lysko PG, Yue TL. 1995. Interleukin- $1 \beta$ induces expression of adhesion molecules in human vascular smooth muscle cells and enhances adhesion of leukocytes to smooth muscle cells. Atherosclerosis 115: 89-98.

Wise CA, Gillum JD, Seidman CE, Lindor NM, Veile R, Bashiardes S, Lovett M. 2002. Mutations in CD2BP1 disrupt binding to PTP PEST and are responsible for PAPA syndrome, an autoinflammatory disorder. $\mathrm{Hum} \mathrm{Mol} \mathrm{Ge}$ net 11: 961-969.

Xu H, Yang J, Gao W, Li L, Li P, Zhang L, Gong YN, Peng X, Xi JJ, Chen S, et al. 2014. Innate immune sensing of bacterial modifications of Rho GTPases by the Pyrin inflammasome. Nature 513: 237-241.

Yang CA, Chiang BL. 2015. Inflammasomes and human autoimmunity: A comprehensive review. J Autoimmun 61: $1-8$.

Yeon HB, Lindor NM, Seidman JG, Seidman CE. 2000. Pyogenic arthritis, pyoderma gangrenosum, and acne syndrome maps to chromosome 15q. Am J Hum Genet 66: 1443-1448.

Yu JW, Fernandes-Alnemri T, Datta P, Wu J, Juliana C, Solorzano L, McCormick M, Zhang Z, Alnemri ES. 2007. Pyrin activates the ASC pyroptosome in response to engagement by autoinflammatory PSTPIP1 mutants. Mol Cell 28: 214-227.

Zemer D, Pras M, Sohar E, Modan M, Cabili S, Gafni J. 1986. Colchicine in the prevention and treatment of the amyloidosis of familial Mediterranean fever. N Engl J Med 314: 1001-1005.

Zhong FL, Mamai O, Sborgi L, Boussofara L, Hopkins R, Robinson K, Szeverenyi I, Takeichi T, Balaji R, Lau A, et al 2016. Germline NLRP1 mutations cause skin inflammatory and cancer susceptibility syndromes via inflammasome activation. Cell 167: 187-202. 


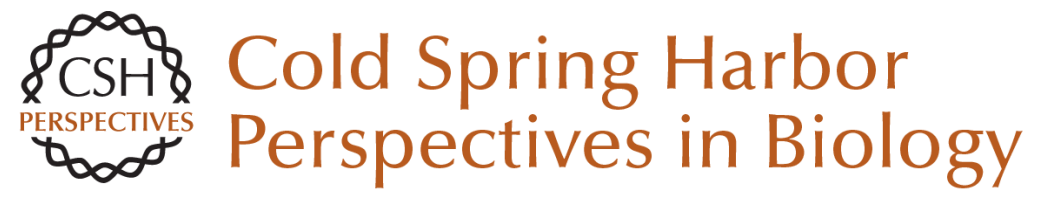

\section{Inflammasome-Dependent Cytokines at the Crossroads of Health and Autoinflammatory Disease}

Hanne Van Gorp, Nina Van Opdenbosch and Mohamed Lamkanfi

Cold Spring Harb Perspect Biol 2019; doi: 10.1101/cshperspect.a028563 originally published online October 16, 2017

\section{Subject Collection Cytokines}

Interleukin (IL)-33 and the IL-1 Family of Cytokines

-Regulators of Inflammation and Tissue

Homeostasis

Ajithkumar Vasanthakumar and Axel Kallies

Targeting IL-10 Family Cytokines for the Treatment of Human Diseases

Xiaoting Wang, Kit Wong, Wenjun Ouyang, et al.

Cytokine-Mediated Regulation of CD8 T-Cell Responses During Acute and Chronic Viral Infection

Masao Hashimoto, Se Jin Im, Koichi Araki, et al.

Cytokines in Cancer Immunotherapy

Thomas A. Waldmann

The Tumor Necrosis Factor Family: Family Conventions and Private Idiosyncrasies David Wallach

The Interferon (IFN) Class of Cytokines and the IFN Regulatory Factor (IRF) Transcription Factor Family

Hideo Negishi, Tadatsugu Taniguchi and Hideyuki

Yanai
Interferon $\gamma$ and Its Important Roles in Promoting and Inhibiting Spontaneous and Therapeutic Cancer Immunity

Elise Alspach, Danielle M. Lussier and Robert D. Schreiber

Inflammasome-Dependent Cytokines at the Crossroads of Health and Autoinflammatory Disease

Hanne Van Gorp, Nina Van Opdenbosch and Mohamed Lamkanfi

Innate Lymphoid Cells (ILCs): Cytokine Hubs

Regulating Immunity and Tissue Homeostasis Maho Nagasawa, Hergen Spits and Xavier Romero Ros

T Helper Cell Differentiation, Heterogeneity, and

Plasticity Jinfang Zhu

Development, Diversity, and Function of Dendritic

Cells in Mouse and Human

David A. Anderson III, Kenneth M. Murphy and Carlos G. Briseño

Cytokines and Long Noncoding RNAs Susan Carpenter and Katherine A. Fitzgerald

For additional articles in this collection, see http://cshperspectives.cshlp.org/cgi/collection/

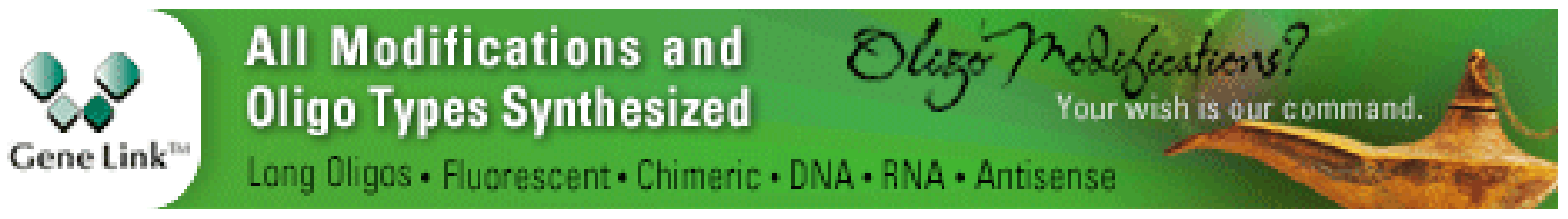


Role of the $\beta$ Common $(\beta \mathrm{c})$ Family of Cytokines in Health and Disease

Timothy R. Hercus, Winnie L. T. Kan, Sophie E. Broughton, et al.

Interleukin (IL)-12 and IL-23 and Their Conflicting Roles in Cancer Juming Yan, Mark J. Smyth and Michele W.L. Teng
Negative Regulation of Cytokine Signaling in Immunity

Akihiko Yoshimura, Minako Ito, Shunsuke Chikuma, et al.

Cancer Inflammation and Cytokines

Maria Rosaria Galdiero, Gianni Marone and Alberto Mantovani

For additional articles in this collection, see http://cshperspectives.cshlp.org/cgi/collection/

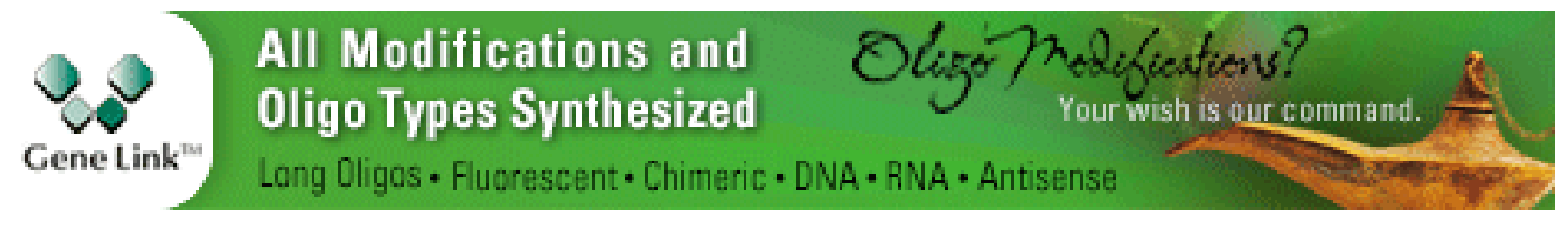

Copyright @ 2019 Cold Spring Harbor Laboratory Press; all rights reserved 